\title{
Immune Gene Expression Profile in Hepatocellular Carcinoma and Surrounding Tissue Predicts Time to Tumor Recurrence
}

\author{
Chiara Carone $^{a}$ Andrea Olivani $^{b}$ Raffaele Dalla Valle ${ }^{c}$ \\ Roberta Manuguerrad Enrico Maria Silinid Tommaso Trentia \\ Gabriele Missale $^{b} \quad$ Elisabetta Cariani ${ }^{a}$ \\ aToxicology and Advanced Diagnostics, Ospedale S. Agostino-Estense, Modena, Italy; \\ bU.O. Infectious Diseases and Hepatology, Azienda Ospedaliero-Universitaria di Parma, \\ Parma, Italy; ${ }^{c}$ Department of Surgery, University of Parma, Parma, Italy; ${ }^{d}$ Pathology Section, \\ Department of Pathology and Laboratory Medicine, University of Parma, Parma, Italy
}

\section{Keywords}

Hepatocellular carcinoma $\cdot$ Immune microenvironment $\cdot$ T lymphocytes $\cdot$ Recurrence $\cdot$

Prognosis

\begin{abstract}
Background: The antitumor immune response may play a major role in the clinical outcome of hepatocellular carcinoma (HCC). We characterized the liver immune microenvironment by direct hybridization of RNA extracted from HCC and nontumorous tissues. Methods: RNA was extracted from frozen liver tissue samples of HCC $(T ; n=30)$ and nontumorous tissues (NT; $n=33$ ) obtained from 38 patients. Matched samples were available for 25 patients. The immune gene expression profile was analyzed with the nCounter GX Human Immunology v2 system (NanoString Technologies), which detects the expression levels of 579 immune response-related genes simultaneously. Results: Since the immune gene expression profile of T and NT tissues was significantly different, the prognostic relevance of the liver immune microenvironment was evaluated in the T and NT samples separately. Unsupervised clustering detected two main clusters of immune gene expression both in T and in NT liver samples. In both cases, the expression clusters identified groups of patients with a significantly different median time to HCC recurrence (TTR) but similar overall survival. Based on T tissue, two groups with median TTR of 19 and 127 months, respectively, were detected $(p<0.005)$. Expression of genes related to T-cell activation was associated with longer TTR. The analysis of NT tissue discriminated subsets of patients with median TTR of 22 and 68 months $(p<0.05)$. In contrast to T tissue, a predominant inflammatory immune environment was associated with shorter TTR. Conclusions: Immune gene expression profiles predictive of TTR could be identified both in HCC and in adjacent cirrhotic tissues. Longer TTR was associated with overexpression in T tissue and downregulation in NT tissue of the immune response and of inflammation-related genes.
\end{abstract}

(C) 2018 S. Karger AG, Basel 


\section{Liver Cancer}

\section{Introduction}

Hepatocellular carcinoma (HCC) represents the second leading cause of cancer-related death worldwide [1]. Despite considerable effort devoted to the clinical and molecular classification of the tumor, HCC-related mortality still parallels its incidence, highlighting the limited success rate of currently available therapeutic options.

HCC frequently develops in a context of liver inflammation, which has been implicated in the carcinogenic process, and plentiful evidence supports a role for the antitumor immune response in the determination of HCC outcome. The density of tumor-infiltrating CD8+ T cells has been associated with patient survival [2], and tumor-associated antigen (TAA)-specific cytotoxic T cells have been detected in $50-70 \%$ of HCC patients [3]. However, the immune landscape of HCC includes tolerance-inducing mechanisms that impair an effective antitumor response. Multiple factors have been implicated in immunomodulatory effects, such as immunoediting of TAAs, mechanisms of tumor immunoevasion, and secretion of immunosuppressive cytokines by the tumor, stromal, and infiltrating cells [4]. The ratio between infiltrating cytotoxic CD8+ $\mathrm{T}$ cells and T-regulatory (Treg) cells [5] and the expression of programmed death-ligand 1 (PD-L1) [6] were reported as independent prognostic factors for disease-free and overall survival.

The success of immune checkpoint inhibition in solid tumors has prompted its application in HCC [7], but reliable biomarkers for prognosis and the identification of patients responsive to immunotherapies are still needed. In the attempt of treatment optimization, the expression of therapeutic targets such as PD-L1 has been tested, showing a low positive and negative predictive value [8]. A recent study has indicated that multigene immunosignatures might represent a more effective tool for the selection of candidates for treatment [9].

In the present study, the immune gene expression profile was determined in HCC and surrounding tissues by direct hybridization of total RNA using the NanoString technology. This approach allows a global characterization of immune function and is particularly suitable for the appraisal of selected gene signatures potentially useful as biomarkers for prognostic classification and therapeutic stratification.

\section{Subjects and Methods}

\section{Patients}

The expression of genes related to the immune response was evaluated in 63 liver samples of HCC (T; $n=30$ ) and nontumorous tissue (NT; $n=33$ ) obtained from 38 patients undergoing surgical resection for HCC. Matched T and NT tissues, derived from the same patient, were available in 25 cases.

Diagnosis of HCC was made by computed tomography and by magnetic resonance imaging in selected cases. Serological markers of hepatitis B virus (HBV) and hepatitis C virus (HCV) were assessed for all patients, as well as anti-human immunodeficiency virus, which was negative for all cases. All patients were treated surgically and received the same postoperative care by the same team of surgeons. Postoperative follow-up was carried out every 4 months for the first 2 years, and every 6 months thereafter.

Risk factors were chronic HCV infection in 31 patients ( 2 with concomitant chronic alcohol use), chronic alcohol use in 5 patients, and chronic HBV infection in 2 patients. The following clinicopathological features of the patients were analyzed: gender, age, etiology of liver disease, number of tumor nodules, cumulative tumor size (sum of the main nodules' diameters), Ishak fibrosis stage, microvascular venous infiltration, and presence of lymphomononuclear infiltrate at histology. The median time to recurrence (TTR) was 27 months and the median survival was 99 months (Table 1). Three patients were excluded from TTR analysis due to recurrence occurring during the first 3 months after surgery.

The study was approved by the local ethics committee (Comitato Etico Indipendente [IRB/IEC] dell'Azienda Ospedaliera di Parma, Parma, Italy), and the patients gave their written informed consent to participate in the study. 


\section{Liver Cancer}

Table 1. Epidemiological, clinical, and pathological characteristics of the patients

\begin{tabular}{l|l}
\hline Liver Cancer 2018;7:277-294 \\
\hline DOI: 10.1159/000486764 & $\begin{array}{l}\text { C 2018 S. Karger AG, Basel } \\
\text { www.karger.com/lic }\end{array}$ \\
\hline
\end{tabular}

Carone et al.: Prognostic Correlates of the HCC Immune Landscape

$\begin{array}{lc}\text { Patients, } n & 38 \\ \text { Gender (M/F), } n & 25 / 13 \\ \text { Mean age } \pm \text { SD, years } & 67.1 \pm 9.7 \\ \text { Anti-HCV positive }^{1}, n & 31 \\ \text { HBsAg positive, } n^{\text {Alcohol use }}, n & 2 \\ \text { Number of HCCs }(1 />1) & 7 \\ \text { Mean HCC size } \pm \text { SD, mm } & 28 / 10 \\ \text { Ishak fibrosis stage }<5 / \geq 5, n & 49.3 \pm 22.4 \\ \text { Microvascular invasion, } n & 10 / 28 \\ \text { Lymphomononuclear infiltrate at histology, } n & 19 \\ \text { Median TTR, months } & 9 \\ \text { Median OS, months } & 27 \\ \end{array}$

M, male; F, female; HCV, hepatitis C virus; HBsAg, hepatitis B surface antigen; HCC, hepatocellular carcinoma; TTR, time to recurrence; OS, overall survival. ${ }^{1}$ Two patients had both risk factors.

Gene Expression Analysis

The tissue samples were immediately frozen in liquid nitrogen and stored at $-80^{\circ} \mathrm{C}$. RNA was extracted using the Total RNA Purification Kit (Norgen Biotek Corp., Thorold, ON, Canada).

The immune gene expression profile was characterized with the nCounter ${ }^{\circledR}$ GX Human Immunology v2 system (NanoString Technologies, Seattle, WA, USA), which relies on the direct hybridization of total RNA with fluorescent barcoded probes complementary to 579 immune response-related genes. To normalize the results, 6 positive controls at different concentrations and 8 negative controls are also provided. A commercial normal liver RNA sample (Ambion Thermo Fisher Scientific, Waltham, MA, USA) was also tested as a control in each experimental session.

The raw data were processed with the specific nSolver 2.6 software (NanoString Technologies). After subtracting background noise (calculated as the mean plus 2 SD of the negative control probes, excluding outliers), intra-/interassay variability was adjusted according to the signal of the positive control probes. The data were normalized against the ratio between the geometric mean of all positive controls and the geometric mean of the positive controls of each sample. The samples were then normalized for RNA content according to the relative expression of the housekeeping genes provided in the assay.

\section{Validation of NanoString Results by Real-Time PCR Analysis}

The NanoString results were confirmed by reverse transcription-real-time PCR (RT-PCR) on a subset of 51 RNA samples (HCC: $n=27$; NT liver: $n=24$ ) available for analysis. Random-primed first-strand cDNA was synthesized with SuperScript ${ }^{\circledR}$ VILO $^{\mathrm{TM}}$ MasterMix (Invitrogen ${ }^{\mathrm{TM}}$; Thermo Fisher Scientific, Waltham, MA, USA) and amplified in duplicate with TaqMan ${ }^{\circledR}$ Gene-Expression Assays specific for 11 target genes selected among relevant checkpoint genes and potential key regulatory genes identified by bioinformatic analysis of the NanoString data. Human $\beta$-glucuronidase (GUSB) was selected among the NanoString housekeeping genes and amplified in duplex with each target to be used as a reference gene. A list of TaqMan assays and their identifiers is provided in online supplementary Table 1 (for all online suppl. material, see www. karger.com/doi/10.1159/000486764).

Amplification was carried out with $\operatorname{TaqMan}^{\circledR}$ Gene Expression Master Mix (Applied Biosystems ${ }^{\circledR}$; Thermo Fisher Scientific) on a Rotor Gene Q thermal cycler (Qiagen, Hilden, Germany). A cDNA synthesized from a commercial normal human liver RNA sample (Ambion; Thermo Fisher Scientific) was run in duplicate in each experiment to check for variability between runs. Target gene RNA amounts are expressed as $2^{-\Delta \mathrm{Ct}}$ ( $\Delta \mathrm{Ct}$ : difference between target gene and reference gene threshold cycle).

\section{Statistical Analysis}

Differences between groups in continuous variables were analyzed by the Mann-Whitney test or Wilcoxon matched-pairs test, as appropriate, whereas categorical variables were compared by Fisher's exact test. 


\section{Liver Cancer}

Carone et al.: Prognostic Correlates of the HCC Immune Landscape

Survival curves were estimated by the Kaplan-Meier method and compared by the log-rank test. Continuous variables were classified according to values lower or higher than median values. Stepwise Cox proportional-hazards regression was used for multivariate survival analysis. Only variables significantly associated with survival in the univariate analysis were included in the multivariate model. GraphPad Prism and MedCalc were used for analysis. $p<0.05$ (two-tailed) was considered significant.

Unsupervised hierarchical clustering was carried out by Spearman's rank correlation and complete linkage after median centering for both samples and genes, using TIGR MultiExperiment Viewer (MeV) 2.0. For comparative analysis of gene expression, data were analyzed by Mann-Whitney test after correcting $p$ values for multiple testing using a Benjamini-Hochberg false discovery rate of 0.05 ( $q$ value). The $q$ value of a test measures the proportion of false positives incurred (called the false discovery rate) when that particular test is called significant.

For each gene, fold change (FC) was calculated as the ratio between the median expression levels of the gene in each tested group. An absolute difference in $\log _{2} \mathrm{FC} \geq 1.5$ was considered as biologically significant and was used to further select differentially expressed genes.

To assess the correlation between the NanoString and RT-PCR results of each target gene, $\log _{2}$-transformed NanoString normalized counts and relative RT-PCR $2^{-\Delta C t}$ values were represented in a heat map for each sample, plotted in a similarity matrix by Pearson correlation, and then subjected to unsupervised hierarchical clustering according to Spearman's correlation by average linkage using Morpheus software (Broad Institute; https://software.broadinstitute.org/morpheus/). For each target gene, both NanoString and RT-PCR data were analyzed for statistical differences between each prognostic group (T1 vs. T2 and NT1 vs. NT2).

Differentially expressed genes with an absolute $\log _{2} \mathrm{FC} \geq|1.5|$ and $q<0.05$ were uploaded into Ingenuity Pathway Analysis (Qiagen, Redwood City, CA, USA) for core analysis and identification of the most significant canonical pathways to categorize differentially expressed genes. A Benjamini-Hochberg-adjusted $p$ value $<0.05$ was used as a cutoff for significance. The $z$ score (number of SDs from the mean) was used to determine the overall prediction of activation or inhibition by positive or negative values, respectively. Biological significance was ascribed to an activation/inhibition value of a $z$ score $>2 /<-2$.

To improve the understanding of interactions between differentially expressed genes, protein-protein interaction (PPI) networks were generated with the STRING database version 10.5 (http://string-db.org/), an online resource for the assessment and integration of direct (physical) and indirect (functional) PPI [10]. The differentially expressed genes were mapped onto STRING and then visualized with Cytoscape version 3.5.1, an open-source platform for network analysis [11]. To increase the likelihood of detecting biologically meaningful, specific, and reproducible PPI, a combined score [10] (confidence score derived from 7 independent sources of evidence) $\geq 0.7$ was set as a cutoff. The nodes (proteins) with the highest degree scores (numbers of neighbors) were considered as possible hub genes (proteins).

\section{Results}

Hierarchical Clustering of Immune Gene Expression

Unsupervised clustering of immune gene expression profiles showed an almost complete separation of T from NT tissues (Fig. 1). One hundred and one genes were differentially expressed between the T and NT samples. Fifteen genes were overexpressed and 86 genes were downregulated. Liver X receptor (LXR)/retinoic X receptor (RXR) activation and peroxisome proliferator-activated receptor (PPAR) signaling were predicted to be activated in $\mathrm{T}$ versus NT tissue, whereas $\mathrm{p} 38$ mitogen-activated protein kinase (MAPK) signaling, B-cell receptor signaling, phospholipase $\mathrm{C}$ signaling, and the role of nuclear factor of activated $\mathrm{T}$ cells (NFAT) in regulation of the immune response were predicted to be inhibited (Table 2).

\section{Prognostic Implication of Immune Gene Expression}

Due to the differential immune gene expression profile of $\mathrm{T}$ and NT tissues, the possible prognostic relevance of the liver immune microenvironment was evaluated in $\mathrm{T}$ and NT samples separately. Unsupervised clustering of immune genes expressed in $\mathrm{T}$ samples 


\section{Liver Cancer}

Fig. 1. Unsupervised hierarchical clustering of hepatocellular carcinoma and nontumorous liver samples. The heat map shows unsupervised hierarchical clustering of both tumor (T; $n=30$ ) and nontumorous (NT; $n=33$ ) samples based on the normalized expression of 579 immune-related genes. Samples are shown in columns and genes in rows. The scale of the gene expression level is indicated by the bar on top of the figure.

\begin{tabular}{l|l}
\hline Liver Cancer 2018;7:277-294 \\
\hline DOI: 10.1159/000486764 & $\begin{array}{l}\text { @ 2018 S. Karger AG, Basel } \\
\text { www.karger.com/lic }\end{array}$ \\
\hline
\end{tabular}

Carone et al.: Prognostic Correlates of the HCC Immune Landscape

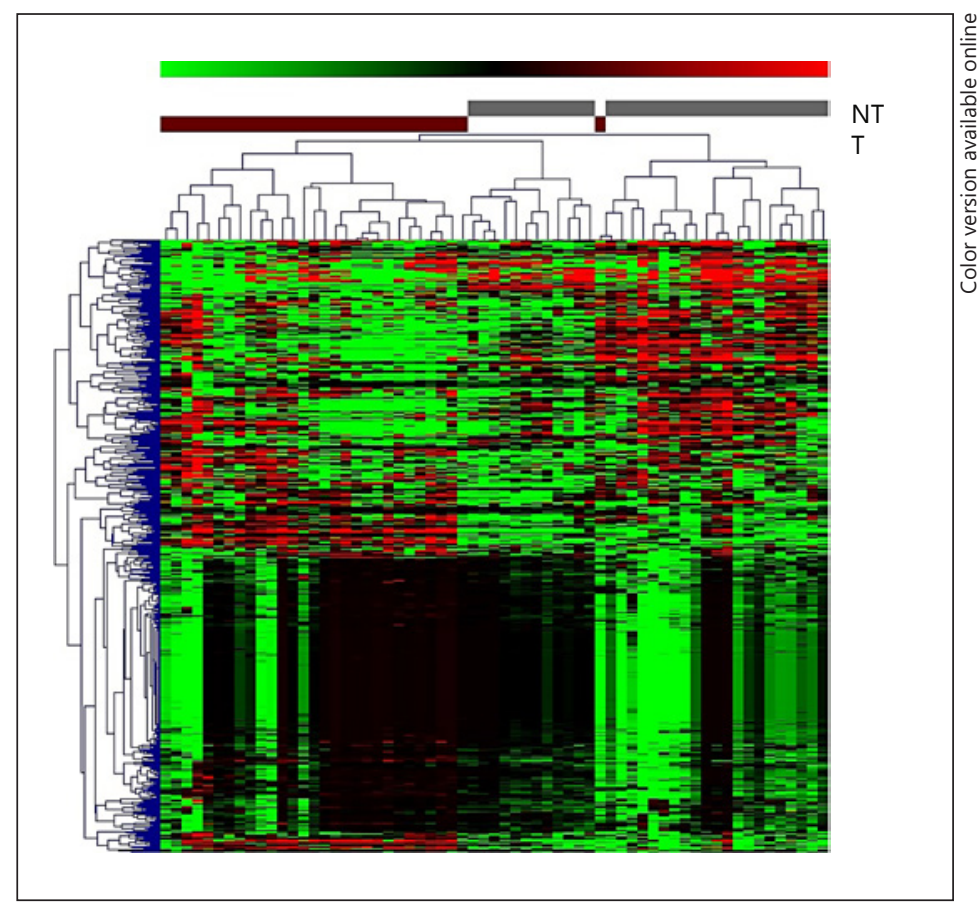

Table 2. Canonical pathways associated with immune response-related genes differentially expressed in hepatocellular carcinoma tissue compared to the nontumorous counterpart

\begin{tabular}{lrr}
\hline Ingenuity canonical pathways & $q$ value & $z$ score \\
\hline LXR/RXR activation & $1.02 \mathrm{E}-08$ & 2.53 \\
p38 MAPK signaling & $1.48 \mathrm{E}-06$ & -2.65 \\
B cell receptor signaling & $2.69 \mathrm{E}-05$ & -2.45 \\
PPAR signaling & $4.47 \mathrm{E}-05$ & 2.45 \\
Phospholipase C signaling & $1.15 \mathrm{E}-04$ & -2.45 \\
Role of NFAT in regulation of the immune response & $1.82 \mathrm{E}-04$ & -2.65 \\
\hline
\end{tabular}

Only pathways with $z$ scores $>2 /<-2$ are shown. LXR, liver X receptor; RXR, retinoic X receptor; MAPK, mitogen-activated protein kinase; PPAR, peroxisome proliferator-activated receptor; NFAT, nuclear factor of activated T cells.

detected two main clusters (T1 and T2) associated with patients' subsets having significantly different median TTR of 127 and 19 months, respectively ( $p=0.0037)$, but no difference in overall survival (Fig. 2).

To evaluate the impact of the immune gene expression profile on recurrence of HCC, the relationship between clinical variables and TTR was analyzed, showing that also alcohol consumption, anti-HCV status, presence of mononuclear infiltrate at histology, and microvascular invasion were significantly associated with TTR (Table 3). It is interesting to note that the presence of tumor mononuclear cell infiltrate at histology had a positive correlation with TTR, consistent with the association between higher immune gene expression (cluster T1) and longer TTR (Fig. 2). Multivariate survival analysis was carried out by Cox regression on all parameters significantly related to TTR by univariate statistical analysis, showing that only HCC immune gene expression profile $(p=0.006)$ and alcohol consumption $(p=0.018)$ were independently associated with TTR. 
Carone et al.: Prognostic Correlates of the HCC Immune Landscape

Table 3. TTR of HCC patients according to clinical characteristics and the HCC immune gene expression cluster

\begin{tabular}{|c|c|c|c|c|c|c|c|}
\hline \multirow[t]{2}{*}{ Variable } & \multirow[t]{2}{*}{ Value } & \multicolumn{3}{|c|}{ Univariate } & \multicolumn{3}{|c|}{ Multivariate } \\
\hline & & $p$ value & HR & $95 \% \mathrm{CI}$ & $p$ value & HR & $95 \% \mathrm{CI}$ \\
\hline Age & $>67$ vs. $\leq 67$ years & 0.21 & 2.17 & $0.65-7.19$ & & & \\
\hline Gender & M vs. F & 0.45 & 0.59 & $0.15-2.31$ & & & \\
\hline HCC nodules & >1 vs. 1 & 0.31 & 1.89 & $0.55-6.51$ & & & \\
\hline Nodule size & $>50$ vs. $\leq 50 \mathrm{~mm}$ & 0.57 & 1.37 & $0.46-4.08$ & & & \\
\hline HBsAg & pos. vs. neg. & 0.87 & 0.88 & $0.20-3.95$ & & & \\
\hline Anti-HCV & pos. vs. neg. & 0.02 & 3.69 & $1.22-11.18$ & & & \\
\hline Alcohol use & pos. vs. neg. & 0.03 & 0.30 & $0.10-0.86$ & 0.018 & 0.10 & $0.015-0.67$ \\
\hline Microvascular invasion & pos. vs. neg. & 0.02 & 3.4 & $1.26-9.18$ & & & \\
\hline Lymphomononuclear infiltrate & pos. vs. neg. & 0.03 & 0.29 & $0.10-0.86$ & & & \\
\hline Ishak fibrosis stage & $\geq 5$ vs. $<5$ & 0.97 & 0.98 & $0.36-2.69$ & & & \\
\hline Tumor tissue cluster & $\mathrm{T} 2$ vs. T1 & 0.004 & 4.82 & $1.67-13.91$ & 0.006 & 10.28 & $1.97-53.68$ \\
\hline
\end{tabular}

Only patients with tumor (T) tissue available for analysis were considered. Patients with recurrence during the first 3 months after treatment $(n=2)$ were excluded from the analysis. TTR, time to recurrence; HCC, hepatocellular carcinoma; M, male; F, female; HBsAg, hepatitis B surface antigen; HCV, hepatitis C virus.

Table 4. Top canonical pathways associated with immune response-related genes differentially expressed in immune gene cluster T2 compared to T1

\begin{tabular}{lll}
\hline Ingenuity canonical pathways & $q$ value & $z$ score \\
\hline Th1 pathway & $2.5119 \mathrm{E}-36$ & -3.80 \\
Th2 pathway & $1.2589 \mathrm{E}-34$ & -2.84 \\
TREM1 signaling & $3.1623 \mathrm{E}-22$ & -4.47 \\
Role of NFAT in regulation of the immune response & $6.3096 \mathrm{E}-21$ & -5.10 \\
iCOS-iCOSL signaling in T helper cells & $1.9953 \mathrm{E}-20$ & -4.24 \\
Dendritic cell maturation & $1.9953 \mathrm{E}-18$ & -4.03 \\
CD28 signaling in T helper cells & $2.5119 \mathrm{E}-18$ & -2.89 \\
PKC- $\theta$ signaling in T lymphocytes & $1.2589 \mathrm{E}-14$ & -3.87 \\
Role of pattern recognition receptors in recognition of bacteria and viruses & $2.5119 \mathrm{E}-14$ & -2.89 \\
Calcium-induced T lymphocyte apoptosis & $1 \mathrm{E}-11$ & -3.32 \\
\hline
\end{tabular}

Only pathways with $z$ scores $>2 /<-2$ are shown. TREM1, triggering receptor expressed on myeloid cells 1 ; NFAT, nuclear factor of activated T cells; iCOS, inducible costimulatory; PKC, protein kinase C.

Overall survival was only associated with alcohol consumption ( $p=0.04$; HR 0.36 ; $95 \%$ CI 0.13-0.97) and anti-HCV status ( $p=0.04$; HR 2.83; 95\% CI 1.05-7.67). Neither of these variables was independently related to overall survival in multivariate statistical analysis (data not shown).

We then analyzed in detail the characteristics of immune gene clusters T1 and T2. Of 199 differentially expressed genes, only 2 were overexpressed in T2 (worse prognosis): RARrelated orphan receptor $\mathrm{C}$ (RORC), regulating the differentiation of thymocytes into Th17 cells [12], and complement component 4-binding protein alpha (C4BPA), which controls activation of the complement cascade through the classic pathway [13].

The most significant pathways predicted to be inhibited in tumors with earlier recurrence and with $z$ scores $<-2$ (Table 4) suggest a relationship between impaired immune cell activation and shorter TTR. 


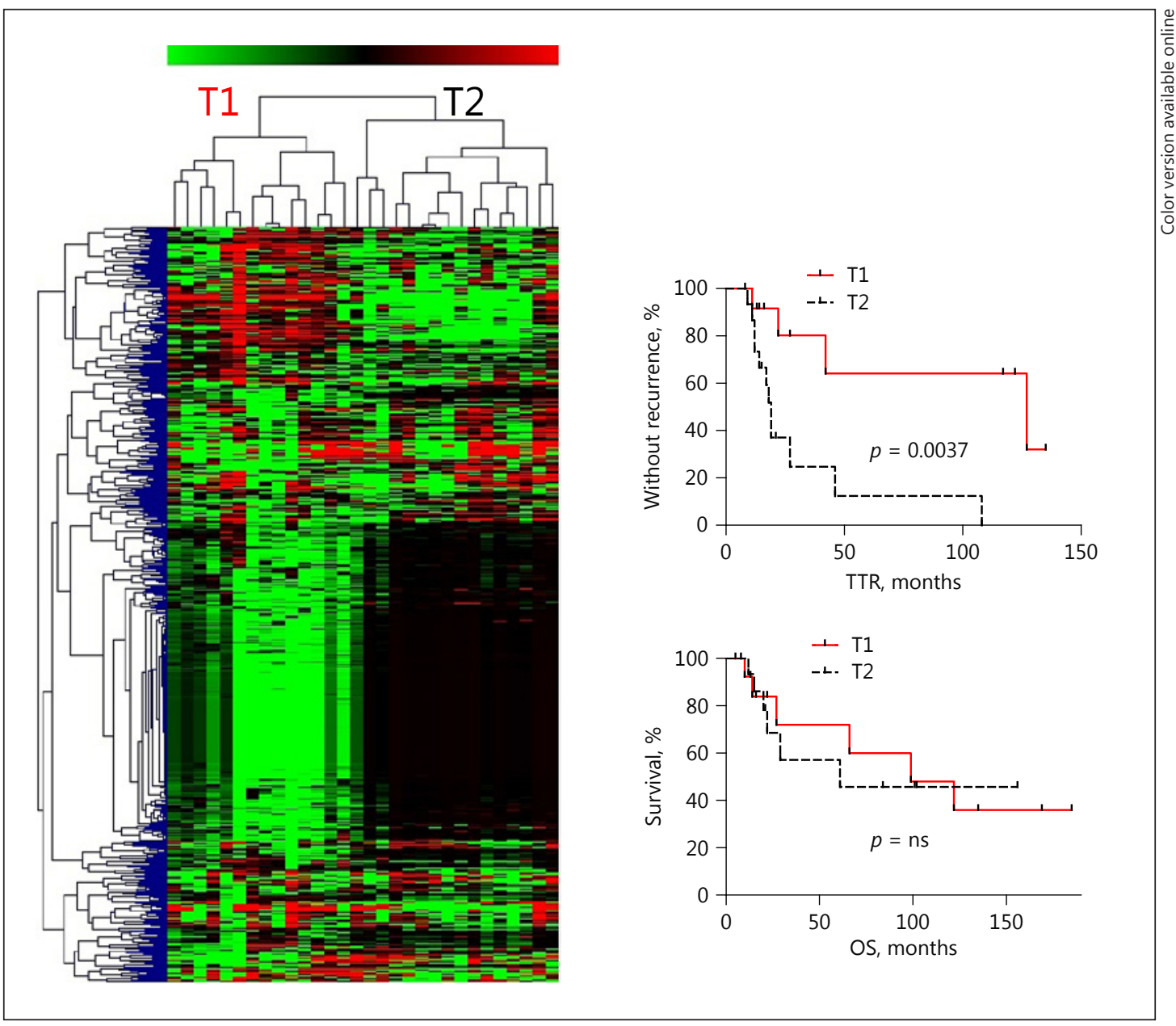

Fig. 2. Prognostic significance of the immune gene expression profile in hepatocellular carcinoma samples. Left: unsupervised hierarchical clustering of hepatocellular carcinoma samples $(n=30)$ based on the normalized expression of 579 immune-related genes. Samples are shown in columns and genes in rows. The scale of the gene expression level is indicated by the bar on top of the figure. Right: Kaplan-Meier curves of time to recurrence (TTR; top) and overall survival (OS; bottom) of the patients included in immune gene clusters T1 and $\mathrm{T} 2$.

Similar to the pattern observed in HCC, the analysis of immune gene expression in NT tissues discriminated two clusters (NT1 and NT2) corresponding to subsets of patients with median TTR of 68 and 22 months, respectively ( $p=0.044)$, whereas no relationship to overall survival was present (Fig. 3). Univariate analysis showed that alcohol consumption and anti-HCV status were also associated with TTR. Multivariate Cox regression analysis identified alcohol use as the only variable independently related to TTR in the subset with NT samples available for analysis (Table 5).

Of 21 genes differentially expressed between the samples included in clusters NT1 and NT2, all were overexpressed in cluster NT2, related to shorter TTR. Only the high-mobility group box 1 (HMGB1) signaling pathway showed a trend towards activation in cluster NT2 $(q=0.0001 ; z$ score $=2)$ (data not shown).

To evaluate whether clinicopathological characteristics might be responsible for the differing prognosis of patients, we performed a statistical analysis, without finding any signif- 


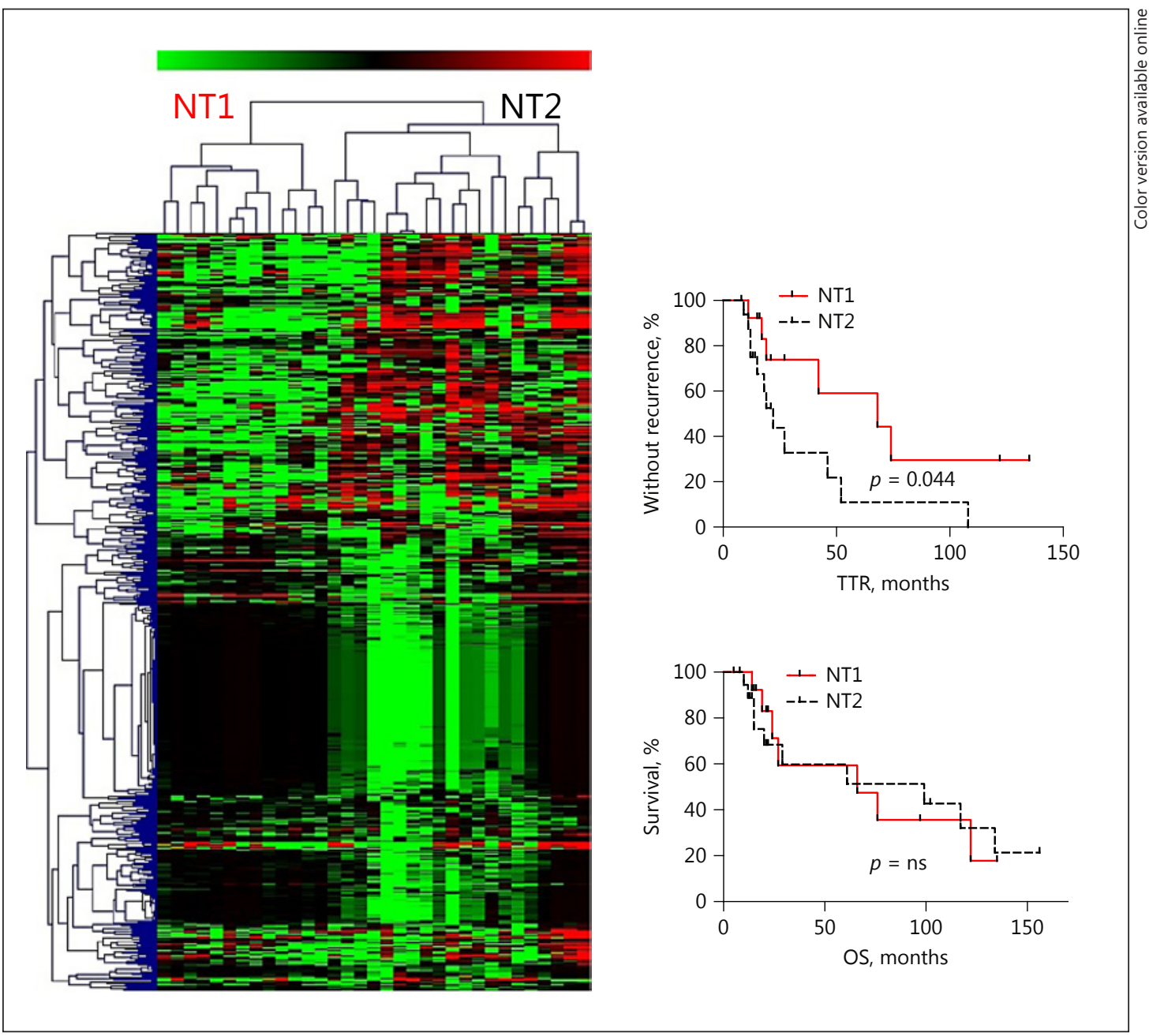

Fig. 3. Prognostic significance of the immune gene expression profile in nontumorous liver samples. Left: unsupervised hierarchical clustering of nontumorous liver samples $(n=33)$ based on the normalized expression of 579 immune-related genes. Samples are shown in columns and genes in rows. The scale of the gene expression level is indicated by the bar on top of the figure. Right: Kaplan-Meier curves of time to recurrence (TTR; top) and overall survival (OS; bottom) of the patients included in immune gene clusters NT1 and NT2.

icant difference between the patients included in the immune gene clusters, despite a higher frequency of HCV infection and of microvascular invasion in clusters T2 and NT2, related to worse prognosis (see online suppl. Table 2).

\section{Characterization of Immune Genes and Cell Types Related to Prognosis}

The expression of key checkpoint genes and their ligands was evaluated in view of their relevance as therapeutic targets. The PDL1, PDCD1, and CD40LG genes were expressed at a low level both in T and NT tissues. Significant upregulation of CTLA4, HAVCR2 (encoding TIM3), CD40LG, LAG3, and TIGIT was detected in cluster T1 compared to T2. CTLA4 was also upregulated in cluster NT2 compared to NT1, and LAG3 in NT compared to T (see online suppl. Fig. 1).

In the attempt of defining the abundance and the functional profile of immune cell populations represented in liver tissue infiltrate, we took advantage of previous work identifying 


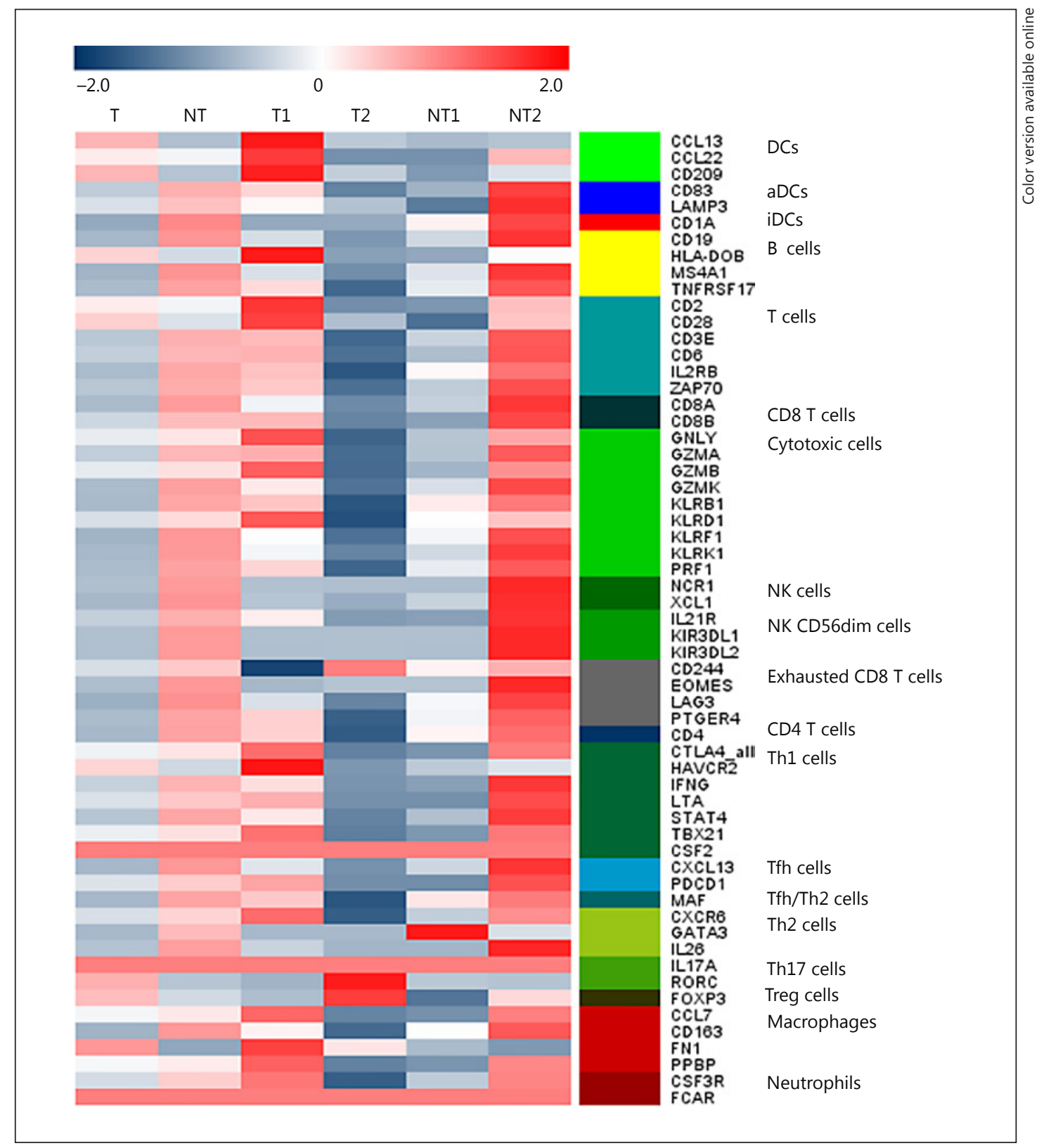

Fig. 4. Prediction of immune cell type distribution in tumor (T) and nontumorous (NT) tissues by a heat map of cell-specific gene expression. $Z$ score results are shown. DCs, dendritic cells; aDCs, activated DCs; iDCs, immature DCs; Tfh, T follicular helper cells.

cell-specific gene expression profiles consistent with flow cytometry and immunohistochemical staining $[14,15]$.

Overall, based on gene expression analysis, the large majority of cell types were predicted to be more represented in NT tissues than in HCC. The only exceptions were dendritic cells (DCs) (generic markers) and the Th17-Treg subsets, the latter being specifically overrepresented in the T2 subgroup, characterized by worse prognosis. Other cell types including DCs and cells of myeloid and lymphoid origin were more frequent in the T1 cluster associated with longer TTR, where cytotoxic cells were especially enriched (Fig. 4). In contrast to HCC 
Carone et al.: Prognostic Correlates of the HCC Immune Landscape

Table 5. TTR of HCC patients according to clinical characteristics and the immune gene expression cluster of nontumorous (NT) liver

\begin{tabular}{|c|c|c|c|c|c|c|c|}
\hline \multirow[t]{2}{*}{ Variable } & \multirow[t]{2}{*}{ Value } & \multicolumn{3}{|c|}{ Univariate } & \multicolumn{3}{|c|}{ Multivariate } \\
\hline & & $p$ value & HR & $95 \% \mathrm{CI}$ & $p$ value & HR & $95 \% \mathrm{CI}$ \\
\hline Age & $>69$ vs. $\leq 69$ years & 0.18 & 1.98 & $0.73-5.31$ & & & \\
\hline Gender & M vs. F & 0.65 & 0.79 & $0.29-2.18$ & & & \\
\hline HCC nodules & >1 vs. 1 & 0.82 & 1.14 & $0.35-3.68$ & & & \\
\hline Nodule size & $>46.5$ vs. $\leq 46.5 \mathrm{~mm}$ & 0.10 & 2.36 & $0.84-6.5$ & & & \\
\hline HBsAg & pos. vs. neg. & - & - & - & & & \\
\hline Anti-HCV & pos. vs. neg. & 0.03 & 3.33 & $1.11-10.00$ & & & \\
\hline Alcohol use & pos. vs. neg. & 0.01 & 0.24 & $0.08-0.72$ & 0.032 & 0.10 & $0.01-0.81$ \\
\hline Microvascular invasion & pos. vs. neg. & 0.10 & 2.25 & $0.87-5.80$ & & & \\
\hline Ishak fibrosis stage & $\geq 5$ vs. $<5$ & 0.92 & 0.95 & $0.35-2.6$ & & & \\
\hline Nontumorous tissue cluster & NT2 vs. NT1 & 0.04 & 2.67 & $1.03-6.98$ & & & \\
\hline
\end{tabular}

Only patients with NT tissue available for analysis were considered. Patients with recurrence during the first 3 months from treatment $(n=3)$ were excluded from the analysis. TTR, time to recurrence; HCC, hepatocellular carcinoma; M, male; F, female; HBsAg, hepatitis B surface antigen; HCV, hepatitis C virus.

tissue, in NT tissue, all cell types, including both activated and exhausted phenotypes, were predicted to be more represented in the NT2 subset, characterized by worse prognosis.

To gain insight into the key genes implicated in the different immune landscapes leading to recurrence in T and NT tissues, PPI networks were generated from the genes differentially expressed between the T2 and T1 or NT2 and NT1 subsets (Fig. 5; online suppl. Table 3). IL-10, lymphocyte-specific protein tyrosine kinase (LCK), FYN, and spleen-associated tyrosine kinase (SYK) were identified as hub genes in the T2 versus T1 comparison, whereas IL-8 and C-C motif chemokine ligand 2 (CCL2) showed the highest degree score in the NT2 versus NT1 comparison (Fig. 5). The network derived from the genes differentially expressed in both comparisons showed that CCL2 is a potential hub gene likely driving opposite regulation of common genes in HCC and surrounding tissue (Fig. 5c).

The results obtained by NanoString for selected checkpoint genes and for potential key regulatory genes identified in this study were confirmed by RT-PCR. The checkpoint genes and genes deregulated both in tumors and in surrounding tissues (CCL2 and IL-8) were tested in all available samples, whereas the analysis of genes differentially expressed only in HCC (including IL-10, SYK, and LCK, identified as major hub genes in the PPI network; TLR2 and TLR4, part of the PPI network and expressed by DCs, differentially distributed between T1 and T2) was restricted to tumor samples. Each method yielded very similar results for all target genes (Fig. 6).

\section{Discussion}

The liver immune milieu is considered one of the main determinants of HCC progression, and immunotherapeutic approaches have gained attention as promising strategies for advanced tumors. However, the molecular background of the immune reaction against HCC is not yet completely understood, and biomarkers predictive of the response to immune therapies are still lacking. A better knowledge of the HCC immune environment could offer clues to the identification of those molecules that drive the impaired antitumor response, thus representing attractive potential therapeutic targets for functional rescue. 


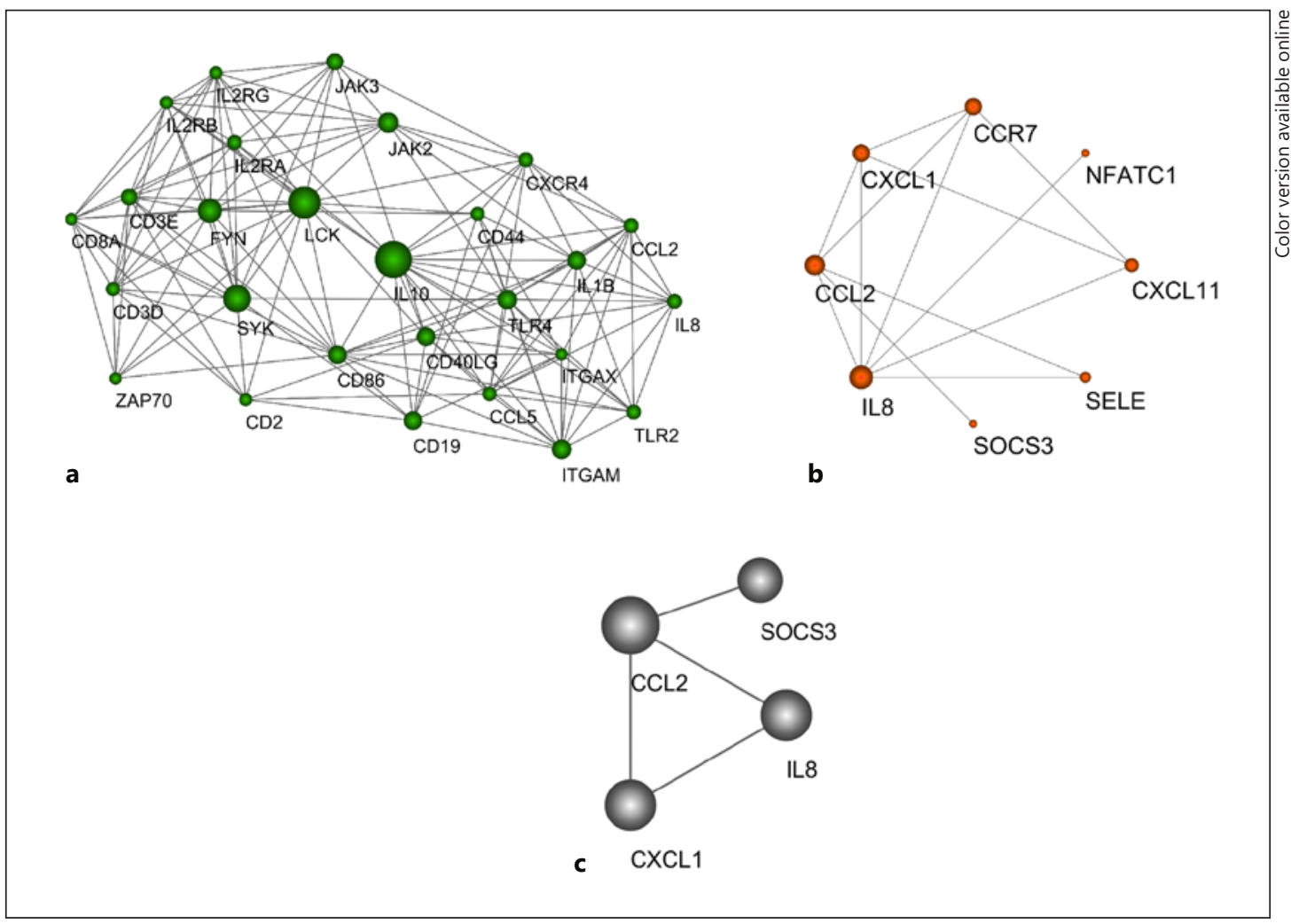

Fig. 5. Protein-protein interaction networks of genes differentially expressed between clusters T2 and T1 (a), NT2 and NT1 (b), and genes common between the two comparisons (c). The node size is proportional to the degree score. Only nodes with a degree score $>20$ are shown in $\mathbf{a}$. a All genes are downregulated. b All genes are upregulated. c Genes show opposite regulation in the two comparisons.

The analysis of immune gene expression in HCC tissue showed an overall downregulation compared to its nontumorous counterpart. Pathway analysis indicated an activation of signaling through LXR and its dimerization partner RXR, acting in concert with PPAR signaling to suppress an inflammatory response [16]. In addition, several interconnected pathways including p38 MAPK, B cell receptor, phospholipase C, and NFAT signaling were predicted to be inhibited, further supporting a generalized downregulation of the inflammatory response, together with impairment of T- and B-cell receptor signaling and of the proliferation and differentiation of immune cells, in HCC compared to nontumorous liver tissue. The p38 MAPK pathway is involved in the synthesis of proinflammatory cytokines and in immune cell proliferation and differentiation [17], and NFAT is a major DNA-binding factor and transcriptional regulator in T cells [18]. A key event in the activation of NFAT is a rise in intracellular calcium concentration initiated by cell surface receptors that stimulate the activation of phospholipase C. In response to T-cell stimulation, the NFAT signaling pathway regulates the functions of cells of the innate and adaptive immune system, being expressed in T and B cells, natural killer (NK) cells, monocytes, and non-immune cells. Altogether, the results of the pathway analysis are consistent with a profound inhibition of both the innate and the adaptive immune response in HCC compared to NT tissue. These results are in line with a recent report describing an immunosuppressive gradient between the nontumorous and the tumor microenvironment, which is characterized by progressively more exhausted immune subsets [19]. 


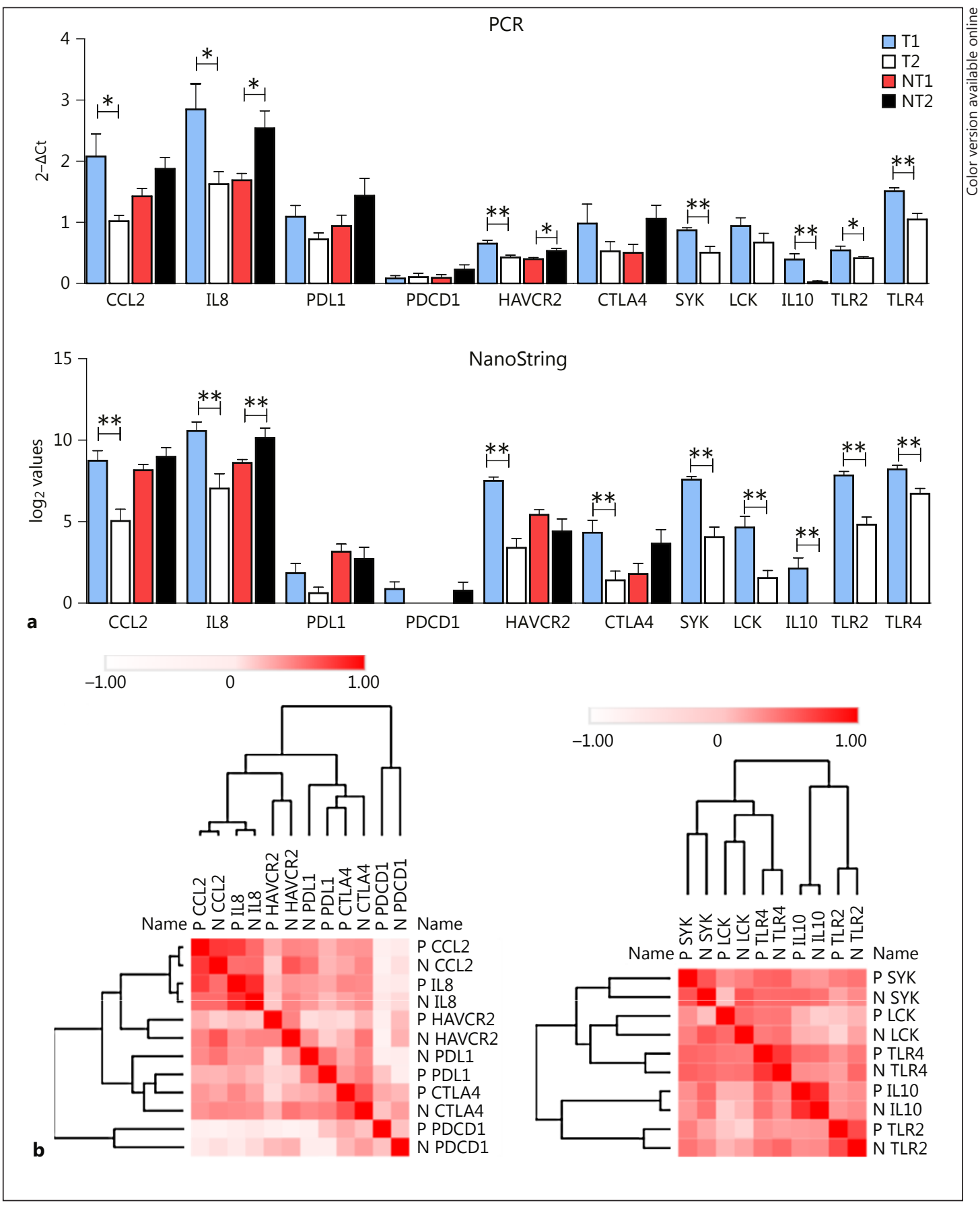

Fig. 6. Validation of the NanoString results by RT-PCR. a Comparison between mRNA abundance determined by RT-PCR (top) and NanoString (bottom) in a subset of 27 hepatocellular carcinoma (HCC) samples (13 from cluster T1, 14 from cluster T2) and 24 surrounding liver tissue samples (11 from cluster NT1 and 13 from cluster NT2). The RT-PCR results are represented as $2^{-\Delta C t}$ values ( $\Delta \mathrm{Ct}=$ target gene $\mathrm{Ct}$ - reference gene $\mathrm{Ct}$ ); the NanoString results are converted into $\log _{2}$. The results are reported as mean values + standard error. b Pearson correlation matrix of mRNA abundance as determined by RT-PCR (P) and NanoString (N). The correlation matrix was subjected to unsupervised hierarchical clustering (average linkage clustering, Spearman's correlation). A subset of genes was tested in all samples (left), whereas genes differentially expressed between the HCC subgroups T1 and T2 were analyzed only in the tumor (T) samples (right). The results obtained for the same target gene are adjacent in the clusters showing a correlation of mRNA expression levels measured by each method. 


\section{Liver
Cancer}

\begin{tabular}{l}
\hline Liver Cancer 2018;7:277-294 \\
\hline DOI: 10.1159/000486764
\end{tabular} \begin{tabular}{l}
$\begin{array}{l}\text { c 2018 S. Karger AG, Basel } \\
\text { www.karger.com/lic }\end{array}$ \\
\hline
\end{tabular}

Carone et al.: Prognostic Correlates of the HCC Immune Landscape

Unsupervised clustering of immune gene profiles identified two subgroups of HCC characterized by significantly different TTR, supporting the impact of an impaired immune environment on the TTR. The results indicate a relationship between earlier recurrence and the predicted inhibition of several strictly interconnected pathways governing the regulation of T-cell function - in particular, of T helper cells - from antigen presentation to the intracellular transduction of activating signals [20]. This peculiar immune landscape was identified as the most significant independent predictor of recurrence. Although we did not detect any significant relationship between immune gene cluster and HCC etiology, we observed a trend towards a higher frequency of HCV infection in the unfavorable clusters T2 and NT2. Therefore, we cannot exclude that the tumor immune landscape predictive of a shorter TTR may be more frequently observed during the course of chronic HCV infection. A history of alcohol consumption was another independent predictor of longer TTR. A previous study showed that non-B, non-C HCC, associated with alcohol consumption in $30 \%$ of cases, was characterized by higher rates of post-resection 5-year recurrence-free survival when compared to HBV- or HCV-linked HCC [21], further suggesting that viral infections may support an intrahepatic microenvironment more favorable for tumor recurrence. It is also worth noting that in the present series, patients with a history of alcohol consumption were significantly younger (about 10 years on average) than patients with viral infections (data not shown).

A distinct profile of immune gene expression in nontumorous liver tissue was associated with a different TTR, without being an independent predictor of TTR. Shorter TTR was related to upregulation of inflammatory gene expression, consistent with activation of the HMGB1 signaling pathway, which has been involved in chemotaxis, activation of innate immune cells, and proinflammatory cytokine secretion [22]. Therefore, an inflammatory environment in nontumorous liver tissue appears to promote tumor progression, different from what was observed in HCC tissue. However, this inflammatory profile was not an independent predictor of recurrence in this cohort of patients, possibly because of the different etiologies that are likely to influence the immune environment of nontumorous liver tissue.

Previous reports have identified immune-related gene signatures in HCC and/or the surrounding liver by microarray profiling [23-28]. In HCC tissue, an interferon (IFN)-related molecular subclass has been associated with increased leukocyte infiltration and tumor apoptosis [23] and with smaller tumor size [25]. Similar to our results, screening of candidate immune response-related genes showed a lower expression in HCC compared to nontumorous liver tissue and a positive association between the expression of inflammatory genes in tumorous tissue and survival [29]. An immune gene profile predictive of patient survival included the chemokine genes CXCL10, CCL5, and CCL2, whose expression correlated with tumor infiltration by CD8+ T cells, NK cells, and Th1 cells [29, 30]. Sia et al. [28] identified markers of inflammatory response in about 25\% of HCCs with evidence of two distinct immune subtypes, characterized by a prevalent adaptive T-cell response and an exhausted immune response, respectively. Interestingly, the patients with an active immune response showed a longer median TTR, consistent with the results of the present study.

Immune gene expression in nontumorous tissue has been related to HCC prognosis [24, 27]. A gene signature associated with shorter survival contained gene sets involved in inflammation, IFN and tumor necrosis factor- $\alpha$ signaling, and activation of NF- $\kappa \mathrm{B}$ [27]. The expression profile derived from nontumorous liver tissue was mostly related to late recurrence occurring more than 2 years after surgery, possibly including the development of de novo tumors arising in cirrhotic tissue [27]. In a recent study, the immune-enriched gene expression signature of nontumorous liver tissue did not reflect the profile of matched tumors, and was associated with shorter survival [28]. Our results are in line with these observations and with our previous study [31], supporting the view that an inflammatory milieu in surrounding liver tissue is related to worse prognosis. 


\section{Liver

Carone et al.: Prognostic Correlates of the HCC Immune Landscape

The complexity of liver infiltrate was further investigated by the relative expression of cell- and function-specific genes. It is worth noting that markers specific for myeloid and lymphoid cells were coexpressed in the same prognostic subsets both in HCC and in NT tissues, suggesting that tissue infiltrate varied in abundance rather than in the relative prevalence of different cell types. We showed that the concurrent expression of genes correlated to cytotoxic activity and inhibitory checkpoint genes in cluster T1, characterized by longer TTR. This observation is consistent with the enhanced expression of inhibitory receptors on TAA-specific lymphocytes infiltrating HCC [32] and other tumors [33]. In this context, the upregulation of inhibitory receptors may represent a regulatory mechanism aimed at preventing overactivation of the antitumor immune response [32]. These observations are of major interest, since gene signatures characterized by Th1 and cytotoxic CD8+ T cell response, as well as by inhibitory mechanisms, have been identified as predictive of the response to checkpoint inhibitors [9]. It is worth noting that by contrast, the only cell populations prevalent in the T2 cluster with worse prognosis were the Th17 and Treg subsets, already associated with worse prognosis in HCC and other tumors $[5,14]$.

To better analyze the distinct molecular mechanisms underlying tumor recurrence in $\mathrm{T}$ and NT liver tissue, a PPI network was generated. Since multiple interactions are suggestive of a central regulatory role, the genes/proteins with the highest degree of connectivity in the network are identified as hubs and expected to drive essential functions [34, 35].

The network analysis of genes differentially expressed between tumors of patients with different TTR highlighted IL-10 as a potential hub gene, a monocyte-secreted cytokine playing a multifaceted role in the regulation of the immune system. Apart from a cytokine-inhibitory function [36], IL-10 has shown a stimulating capacity on CD8+ T-cell and NK-cell cytotoxic activity [37]. In particular, IL-10 plays an immunostimulatory role in the oncological context. Recombinant IL-10 treatment inhibits metastatic dissemination in mice [38,39] and PEGylated recombinant murine IL-10 has been shown to induce IFN- $\gamma$ - and CD8+ T-cell-dependent antitumor immunity [40].

The expression of other predicted hub genes (LCK, SYK, and FYN) involved in immune receptor signaling was downregulated in tumors with a shorter TTR. LCK and FYN are critical elements in T-cell receptor signaling, implicated in T-cell development and differentiation [41]. Moreover, recent results have shown that besides T-cell receptor, Toll-like receptor (TLR) engagement is also involved in T-cell activation by LCK and FYN [42]. SYK is involved in downstream signaling by multiple receptors of the immune system, altogether being a modulator of tumorigenesis either as a tumor promoter or as a tumor suppressor [43]. SYK methylation and loss of SYK protein expression were identified as independent predictors of shorter overall survival in patients with HCC [44].

IL-8 and CCL2 were identified as hub genes in the network derived from genes differentially expressed among NT areas associated with different TTR. IL-8 is secreted by both tumor cells and tumor-associated macrophages, and is involved in neoangiogenesis and metastatic dissemination [45]. In HCC, IL-8 expression has been correlated with clinicopathological features and prognosis [46] and implicated in tumor invasion and metastasis [47]. The role of CCL2 expression within HCC is controversial: it has been associated not only with loss of tumor encapsulation, microvascular invasion, higher TNM stage, shorter overall survival, and higher recurrence rates $[47,48]$, but also with intratumoral infiltration of Th1, CD8+, and NK cells and with good prognosis $[29,30]$. In the present study, individual CCL2 expression was not related to tumor recurrence. However, both CCL2 and IL-8 were part of the gene panel differentially expressed between tissues related to different TTR, with opposite significance of overexpression in tumor and nontumorous tissues. The relevance of CCL2 and IL-8 as central elements in the liver immune environment is further supported by their identification 


\section{Liver Cancer}

as hub genes/proteins in the network derived from differentially expressed genes common to HCC and surrounding liver tissue.

Recent studies showed that CCL2 is secreted from oncogene-induced senescent hepatocytes to recruit CCR2+ immature myeloid cells that clear premalignant senescent cells [49, 50] but promote growth of established HCC through inhibition of antitumor T and NK cells $[48,49]$. CCL2 can also be produced by resident liver cells as hepatic stellate cells, which have been shown to generate a recurrence-favorable environment by facilitating HCC cell migration upon interaction with monocytes [51]. In a murine model of HCC, targeting of CCL2/CCR2 interaction was shown to suppress tumor growth and dissemination, preventing postsurgical recurrence. CCR2 blockade reduced monocyte recruitment and M2 polarization, increasing the number of tumor-infiltrating cytotoxic CD8+ lymphocytes [43]. Therefore, monocyte/ macrophage infiltration is likely to play a dual role in liver carcinogenesis by providing a tumor-prone inflammatory liver environment and suppressing the antitumor immune response [52].

In the present study, the immune landscape of tumor and surrounding tissue was shown to have an impact on tumor recurrence without any significant influence on the overall survival of patients. The survival of patients with HCC is strongly influenced by factors related to the residual liver function and to decompensation of the underlying liver cirrhosis [53]. In addition, the development of new HCC foci with a dissemination potential and immunogenicity different from that of the primary tumor cannot be excluded and may play a role in the subsequent evolution of the disease. It is therefore likely that a favorable immune profile may primarily influence tumor recurrence, without any direct relationship to overall survival.

Despite the huge amount of data already available on the subject, the present report adds new important elements to the characterization of the immune microenvironment of HCC and of its clinical implication. The immune gene-targeted expression profiles offer insight into the infiltrating cell types and the biological mechanisms active in HCC tissue and in the surrounding liver. Our results support the existence of two distinct immunological mechanisms operating in HCC and surrounding cirrhotic tissues. Earlier recurrence was related to a prevalent impairment of T-cell effector function in HCC tissue, and to the presence of an inflammatory milieu in nontumorous liver tissue. The identification of possible molecular drivers of these immune landscapes may be useful for the development of novel prognostic biomarkers and offer clues to therapeutic intervention.

\section{Acknowledgments}

This work was partially supported by the grant Programma di Ricerca Regione-Università 2013 (Regione Emilia Romagna), code PRUa2-2013-00002033, and by an FIRB grant from the Italian Ministry of Education, Universities, and Research, protocol No. RBAP10TPXK. Chiara Carone was supported by a fellowship from AUSL Modena.

\section{Disclosure Statement}

The authors declare no conflict of interest. 
References

1 Ferlay J, Soerjomataram I, Dikshit R, Eser S, Mathers C, Rebelo M, Parkin DM, Forman D, Bray F: Cancer incidence and mortality worldwide: sources, methods and major patterns in GLOBOCAN 2012. Int J Cancer 2015; 136:E359-E386.

-2 Wada Y, Nakashima 0, Kutami R, Yamamoto 0, Kojiro M: Clinicopathological study on hepatocellular carcinoma with lymphocytic infiltration. Hepatology 1998;27:407-414.

-3 Flecken T, Schmidt N, Hild S, Gostick E, Drognitz O, Zeiser R, Schemmer P, Bruns H, Eiermann T, Price DA, Blum HE, Neumann-Haefelin C, Thimme R: Immunodominance and functional alterations of tumor-associated antigen-specific CD8+ T-cell responses in hepatocellular carcinoma. Hepatology 2014;59:1415-1426.

4 Prieto J, Melero I, Sangro B: Immunological landscape and immunotherapy of hepatocellular carcinoma. Nat Rev Gastroenterol Hepatol 2015;12:681-700.

5 Gao Q, Qiu SJ, Fan J, Zhou J, Wang XY, Xiao YS, Xu Y, Li YW, Tang ZY: Intratumoral balance of regulatory and cytotoxic T cells is associated with prognosis of hepatocellular carcinoma after resection. J Clin Oncol 2007; 25:2586-2593

6 Gao Q, Wang XY, Qiu SJ, Yamato I, Sho M, Nakajima Y, Zhou J, Li BZ, Shi YH, Xiao YS, Xu Y, Fan J: Overexpression of PD-L1 significantly associates with tumor aggressiveness and postoperative recurrence in human hepatocellular carcinoma. Clin Cancer Res 2009;15:971-979.

7 Kudo M: Immune checkpoint blockade in hepatocellular carcinoma: 2017 update. Liver Cancer 2016;6:1-12.

8 Gibney GB, Weiner LM, Atkins MB: Predictive biomarkers for checkpoint inhibitor-based immunotherapy. Lancet Oncol 2016;16:e542-e551.

-9 Ayers M, Lunceford J, Nebozhyn M, Murphy E, Loboda A, Kaufman DR, Albright A, Cheng D, Kang SP, Shankaran V, Piha-Paul SA, Yearley J, Seiwert TY, Ribas A, McClanahan TK: IFN- $\gamma$-related mRNA profile predicts clinical response to PD-1 blockade. J Clin Invest 2017;127:2930-2940.

10 Szklarczyk D, Morris JH, Cook H, Kuhn M, Wyder S, Simonovic M, Santos A, Doncheva NT, Roth A, Bork P, Jensen LJ, von Mering C: The STRING database in 2017: quality-controlled protein-protein association networks, made broadly accessible. Nucleic Acids Res 2017;45:D362-D368.

-11 Shannon P, Markiel A, Ozier O, Baliga NS, Wang JT, Ramage D, Amin N, Schwikowski B, Ideker T: Cytoscape: a software environment for integrated models of biomolecular interaction networks. Genome Res 2003;13: 2498-2504.

12 Ivanov II, McKenzie BS, Zhou L, Tadokoro CE, Lepelley A, Lafaille JJ, Cua DJ, Littman DR: The orphan nuclear receptor ROR $\gamma$ t directs the differentiation program of proinflammatory IL-17 ${ }^{+}$T helper cells. Cell 2006;126: 1121-1133.

13 Ermert D, Blom AM: C4b-binding protein: the good, the bad and the deadly. Novel functions of an old friend. Immunol Lett 2016;169:82-92.

14 Bindea G, Mlecnik B, Tosolini M, Kirilovsky A, Waldner M, Obenauf AC, Angell H, Fredriksen T, Lafontaine L, Berger A, Bruneval P, Fridman WH, Becker C, Pagès F, Speicher MR, Trajanoski Z, Galon J: Spatiotemporal dynamics of intratumoral immune cells reveal the immune landscape in human cancer. Immunity 2013;39: 782-795.

15 Danaher P, Warren S, Dennis L, D’Amico L, White A, Disis ML, Geller MA, Odunsi K, Beechem J, Fling SP: Gene expression markers of tumor infiltrating leukocytes. J Immunother Cancer 2017;5:18.

16 Kidani Y, Bensinger SJ: LXR and PPAR as integrators of lipid homeostasis and immunity. Immunol Rev 2012; 249:72-83.

17 Dong C, Davis RJ, Flavell RA: MAP kinases in the immune response. Annu Rev Immunol 2002;20:55-72.

18 Macian F: NFAT proteins: key regulators of T-cell development and function. Nat Rev Immunol 2005;5:472484.

19 Chew V, Lai L, Pan L, Lim CJ, Li J, Ong R, Chua C, Leong JY, Lim KH, Toh HC, Lee SY, Chan CY, Goh BKP, Chung A, Chow PKH, Albani S: Delineation of an immunosuppressive gradient in hepatocellular carcinoma using highdimensional proteomic and transcriptomic analyses. Proc Natl Acad Sci USA 2017;114:E5900-E5909.

20 Brownlie RJ, Zamoyska R: T cell receptor signalling networks: branched, diversified and bounded. Nat Rev Immunol 2013;13:257-269.

-21 Utsunomiya T, Shimada M, Kudo M, Ichida T, Matsui O, Izumi N, Matsuyama Y, Sakamoto M, Nakashima O, Ku Y, Takayama T, Kokudo N; Liver Cancer Study Group of Japan: A comparison of the surgical outcomes among patients with HBV-positive, HCV-positive, and non-B non-C hepatocellular carcinoma: a nationwide study of 11,950 patients. Ann Surg 2015;261:513-520.

22 Lotze MT, Tracey KJ: High-mobility group box 1 protein (HMGB1): nuclear weapon in the immune arsenal. Nat Rev Immunol 2005;5:331-342.

-23 Breuhahn K, Vreden S, Haddad R, Beckebaum S, Stippel D, Flemming P, Nussbaum T, Caselmann WH, Haab BB, Schirmacher P: Molecular profiling of human hepatocellular carcinoma defines mutually exclusive interferon regulation and insulin-like growth factor II overexpression. Cancer Res 2004;64:6058-6064.

24 Budhu A, Forgues M, Ye QH, Jia HL, He P, Zanetti KA, Kammula U, Chen Y, Qin L, Tang ZY, Wang XW: Prediction of venous metastases, recurrence, and prognosis in hepatocellular carcinoma based on a unique immune response signature of the liver microenvironment. Cancer Cell 2006;10:99-111. 
Carone et al.: Prognostic Correlates of the HCC Immune Landscape

25 Chiang DY, Villanueva A, Hoshida Y, Peix J, Newell P, Minguez B, LeBlanc AC, Donovan DJ, Thung SN, Solé M, Tovar V, Alsinet C, Ramos AH, Barretina J, Roayaie S, Schwartz M, Waxman S, Bruix J, Mazzaferro V, Ligon AH, Najfeld V, Friedman SL, Sellers WR, Meyerson M, Llovet JM: Focal gains of VEGFA and molecular classification of hepatocellular carcinoma. Cancer Res 2008;68:6779-6788.

-26 Sakai Y, Honda M, Fujinaga H, Tatsumi I, Mizukoshi E, Nakamoto Y, Kaneko S: Common transcriptional signature of tumor-infiltrating mononuclear inflammatory cells and peripheral blood mononuclear cells in hepatocellular carcinoma patients. Cancer Res 2008;68:10267-10279.

27 Hoshida Y, Villanueva A, Kobayashi M, Peix J, Chiang DY, Camargo A, Gupta S, Moore J, Wrobel MJ, Lerner J, Reich M, Chan JA, Glickman JN, Ikeda K, Hashimoto M, Watanabe G, Daidone MG, Roayaie S, Schwartz M, Thung S, Salvesen HB, Gabriel S, Mazzaferro V, Bruix J, Friedman SL, Kumada H, Llovet JM, Golub TR: Gene expression in fixed tissues and outcome in hepatocellular carcinoma. N Engl J Med 2008;359:1995-2004.

28 Sia D, Jiao Y, Martinez-Quetglas I, Kuchuk O, Villacorta-Martin C, Castro de Moura M, Putra J, Camprecios G, Bassaganyas L, Akers N, Losic B, Waxman S, Thung SN, Mazzaferro V, Esteller M, Friedman SL, Schwartz M, Villanueva A, Llovet JM: Identification of an immune-specific class of hepatocellular carcinoma, based on molecular features. Gastroenterology 2017;153:812-826.

29 Chew V, Tow C, Teo M, Wong HL, Chan J, Gehring A, Loh M, Bolze A, Quek R, Lee VK, Lee KH, Abastado JP, Toh HC, Nardin A: Inflammatory tumour microenvironment is associated with superior survival in hepatocellular carcinoma patients. J Hepatol 2010;52:370-379.

-30 Chew V, Chen J, Lee D, Loh E, Lee J, Lim KH, Weber A, Slankamenac K, Poon RT, Yang H, Ooi LL, Toh HC, Heikenwalder M, Ng IO, Nardin A, Abastado JP: Chemokine-driven lymphocyte infiltration: an early intratumoural event determining long-term survival in resectable hepatocellular carcinoma. Gut 2012;61:427-438.

-31 Cariani E, Pilli M, Zerbini A, Rota C, Olivani A, Pelosi G, Schianchi C, Soliani P, Campanini N, Silini EM, Trenti T, Ferrari C, Missale G: Immunological and molecular correlates of disease recurrence after liver resection for hepatocellular carcinoma. PLoS One 2012;7:e32493.

-32 Zhou G, Sprengers D, Boor PPC, Doukas M, Schutz H, Mancham S, Pedroza-Gonzalez A, Polak WG, de Jonge J, Gaspersz M, Dong H, Thielemans K, Pan Q, IJzermans JNM, Bruno MJ, Kwekkeboom J: Antibodies against immune checkpoint molecules restore functions of tumor-Infiltrating $\mathrm{T}$ cells in hepatocellular carcinomas. Gastroenterology 2017;153:1107-1119.

-33 Gros A, Robbins PF, Yao X, Li YF, Turcotte S, Tran E, Wunderlich JR, Mixon A, Farid S, Dudley ME, Hanada K, Almeida JR, Darko S, Douek DC, Yang JC, Rosenberg SA: PD-1 identifies the patient-specific CD8 ${ }^{+}$tumorreactive repertoire infiltrating human tumors. J Clin Invest 2014;124:2246-2259. Albert R, Barabasi AL: Statistical mechanics of complex networks. Rev Modern Phys 2002;74:47-97.

-35 van Dam S, Võsa U, van der Graaf A, Franke L, de Magalhães JP: Gene co-expression analysis for functional classification and gene-disease predictions. Brief Bioinform 2017, Epub ahead of print.

-36 de Waal Malefyt R, Abrams J, Bennett B, Figdor CG, de Vries JE: Interleukin 10 (IL-10) inhibits cytokine synthesis by human monocytes: an autoregulatory role of IL-10 produced by monocytes. J Exp Med 1991;174: 1209-1220.

-37 Moore KW, de Waal Malefyt R, Coffman RL, O'Garra A: Interleukin-10 and the interleukin-10 receptor. Annu Rev Immunol 2001;19:683-765.

-38 Zheng LM, Ojcius DM, Garaud F, Roth C, Maxwell E, Li Z, Rong H, Chen J, Wang XY, Catino JJ, King I: Interleukin-10 inhibits tumor metastasis through an NK cell-dependent mechanism. J Exp Med 1996;184:579-584.

39 Fujii S, Shimizu K, Shimizu T, Lotze MT: Interleukin-10 promotes the maintenance of antitumor CD8 ${ }^{+}$T-cell effector function in situ. Blood 2001;98:2143-2151.

40 Mumm JB, Emmerich J, Zhang X, Chan I, Wu L, Mauze S, Blaisdell S, Basham B, Dai J, Grein J, Sheppard C, Hong K, Cutler C, Turner S, LaFace D, Kleinschek M, Judo M, Ayanoglu G, Langowski J, Gu D, Paporello B, Murphy E, Sriram V, Naravula S, Desai B, Medicherla S, Seghezzi W, McClanahan T, Cannon-Carlson S, Beebe AM, Oft M: IL-10 elicits IFN $\gamma$-dependent tumor immune surveillance. Cancer Cell 2011;20:781-796.

-41 Salmond RJ, Filby A, Qureshi I, Caserta S, Zamoyska R: T-cell receptor proximal signalling via the Src-family kinases, Lck and Fyn, influences T-cell activation, differentiation, and tolerance. Immunol Rev 2009;228:9-22.

-42 Sharma N, Akhade AS, Qadri A: Src kinases central to T-cell receptor signalling regulate TLR-activated innate immune responses from human T cells. Innate Immun 2016;22:238-244.

43 Seda V, Mraz M: B-cell receptor signalling and its crosstalk with other pathways in normal and malignant cells. Eur J Haematol 2015;94:193-205.

44 Yuan Y, Wang J, Li J, Wang L, Li M, Yang Z, Zhang C, Dai JL: Frequent epigenetic inactivation of spleen tyrosine kinase gene in human hepatocellular carcinoma. Clin Cancer Res 2006;12:6687-6695.

45 Waugh DJ, Wilson C: The interleukin-8 pathway in cancer. Clin Cancer Res 2008;14:6735-6741.

-46 Ren Y, Poon RT, Tsui HT, Chen WH, Li Z, Lau C, Yu WC, Fan ST: Interleukin-8 serum levels in patients with hepatocellular carcinoma: correlations with clinicopathological features and prognosis. Clin Cancer Res 2003; 9:5996-6001.

47 Huang W, Chen Z, Zhang L, Tian D, Wang D, Fan D, Wu K, Xia L: Interleukin-8 induces expression of FOXC1 to promote transactivation of CXCR1 and CCL2 in hepatocellular carcinoma cell lines and formation of metastases in mice. Gastroenterology 2015;149:1053-1067.

48 Li X, Yao W, Yuan Y, Chen P, Li B, Li J, Chu R, Song H, Xie D, Jiang X, Wang H: Targeting of tumour-infiltrating macrophages via CCL2/CCR2 signalling as a therapeutic strategy against hepatocellular carcinoma. Gut 2017; 66:157-167. 
49 Eggert T, Wolter K, Ji J, Ma C, Yevsa T, Klotz S, Medina-Echeverz J, Longerich T, Forgues M, Reisinger F, Heikenwalder M, Wang XW, Zender L, Greten TF: Distinct functions of senescence-associated immune responses in liver tumor surveillance and tumor progression. Cancer Cell 2016;30:533-547.

50 Kang TW, Yevsa T, Woller N, Hoenicke L, Wuestefeld T, Dauch D, Hohmeyer A, Gereke M, Rudalska R, Potapova A, Iken M, Vucur M, Weiss S, Heikenwalder M, Khan S, Gil J, Bruder D, Manns M, Schirmacher P, Tacke F, Ott M, Luedde T, Longerich T, Kubicka S, Zender L: Senescence surveillance of pre-malignant hepatocytes limits liver cancer development. Nature 2011;479:547-551.

51 Ji J, Eggert T, Budhu A, Forgues M, Takai A, Dang H, Ye Q, Lee JS, Kim JH, Greten TF, Wang XW: Hepatic stellate cell and monocyte interaction contributes to poor prognosis in hepatocellular carcinoma. Hepatology 2015; 62:481-495.

52 Tacke F: Targeting hepatic macrophages to treat liver diseases. J Hepatol 2017;66:1300-1312.

53 Cabibbo G, Petta S, Barbara M, Attardo S, Bucci L, Farinati F, Giannini EG, Negrini G, Ciccarese F, Rapaccini GL, Di Marco M, Caturelli E, Zoli M, Borzio F, Sacco R, Virdone R, Marra F, Mega A, Morisco F, Benvegnù L, Gasbarrini A, Svegliati-Baroni G, Foschi FG, Olivani A, Masotto A, Nardone G, Colecchia A, Persico M, Craxì A, Trevisani F, Cammà C; Italian Liver Cancer (ITA.LI.CA) Group: Hepatic decompensation is the major driver of death in HCVinfected cirrhotic patients with successfully treated early hepatocellular carcinoma. J Hepatol 2017;67:65-71. 